\title{
Visible near-infrared reflectance spectroscopy as a predictive indicator of soil properties
}

\author{
D. Summers*, M. Lewis, B. Ostendorf, D. Chittleborough \\ School of Earth and Environmental Sciences, The University of Adelaide, Adelaide, South Australia 5005, Australia
}

\section{A R T I C L E I N F O}

\section{Article history:}

Received 21 April 2008

Received in revised form 17 March 2009

Accepted 5 May 2009

\section{Keywords:}

Visible near-infrared reflectance

Soil properties

Partial least squares regression

\begin{abstract}
A B S T R A C T
It is becoming increasingly important to improve spatial resolutions of soil maps as a fundamental information layer for studying ecological processes and to tackle land degradation. There is growing interest in the use of remote sensing technologies to assist the identification and delineation of spatial variation in soils. This paper investigates whether selected properties of extensively weathered, low fertility soils can be predicted using high-resolution reflectance spectra over the range 400-2500 $\mathrm{nm}$. Clay content, carbonate concentration, organic carbon content and iron oxide content were analysed for 300 soil samples collected from the Jamestown, Belalie district, South Australia. The paper also examines the efficacy of this soil analysis methodology to supplement or replace traditional soil sampling in soil survey to increase sampling density and improve the spatial resolution of soil maps.

Reflectance spectra were obtained from air-dried samples under controlled laboratory conditions using an ASD FieldSpec Pro spectroradiometer. Partial least squares regression was used to examine relationships between soil mineralogy, clay content and organic carbon and the reflectance spectra and identify the wavelengths contributing to prediction of these soil properties. Results show that it is possible to predict clay content, soil organic carbon, iron oxide content and carbonate content. Crossvalidation $R^{2}$ values for all analyses were above 0.5 and the residual prediction difference (RPD) was acceptable for all soil properties. Carbonate and clay content were more accurately predicted than iron oxide and organic carbon. All samples were collected from the same geographical area such that they represented physical properties over a naturally occurring range and provide a prediction that could be related to subsequent image analysis or be used to carry out local scale soil survey. A rapid and reliable form of soil mapping could be developed from this methodology.
\end{abstract}

(c) 2009 Elsevier Ltd. All rights reserved.

\section{Introduction}

The classification, mapping and monitoring of soils is an important underpinning of modern day natural resource management. Regional scale soil maps are traditionally produced by dividing the landscape into mapping units through air-photo and landscape interpretation from which sample sites are chosen to characterise the soils. For regional planning these maps provide an excellent resource, but they do not provide sufficient detail for localised soil and land management. Whereas soil variability within each of these mapping units is often acknowledged in the map and accompanying report, it is not depicted or quantified. Increasing concern over land degradation, agricultural productivity and the loss of ecological services has led to a desire for greater understanding of land resources and processes at scales larger than 1:50 000 scales.

\footnotetext{
* Corresponding author.

E-mail address: david.summers@adelaide.edu.au (D. Summers).
}

Around the world governments are investing in programs to better understand soil variability and create soil databases to better inform landscape planning and management decisions. In South Australia the soils of the agricultural districts have been mapped and information presented on maps at 1:50000 and 1:100 000 scale (Soil and Land Program, 2007). While these maps provide an excellent regional planning tool, finer spatial resolution information is required to improve land management decisions at farm scale, and to assist understanding and modelling of problems such as diminishing biodiversity and dryland salinity. Unlike the agricultural districts, there is a paucity of data on the nature and distribution of soils in South Australia's pastoral zones. The pastoral districts cover large areas and contribute substantially to the State's economic productivity. These areas would benefit greatly from improved understanding of soil properties and their variability as well as vegetation condition, ecology and biodiversity. Recent studies in Australia's arid region for example, have called for improved understanding of soil heterogeneity as inputs for the monitoring of ecology and biodiversity, citing the lack of spatial resolution as an impediment (Clarke, 2008). Similar inputs 
have been used in other parts of the world to predict vegetation community distributions (Miller et al., 2002).

Creating these maps and improving the spatial resolution of existing maps to provide greater detail about soil variability can be prohibitively expensive by traditional soil survey procedures (Sumfleth and Duttmann, 2007) and can only be justified for the most intensive agricultural systems. Pedotransfer functions have been employed to reduce the expense of intensive soil mapping by using surrogates that are relatively inexpensive to measure, as well as to predict less readily measured soil properties. Examples of this include using soil colour to predict organic carbon content and using mechanical resistance as an indicator of bulk density and clay content (McBratney et al., 2002). However effective these functions are for some applications, pedotransfer functions do not provide a direct measurement of soil properties nor are they provided for all soil properties of interest. Information or indicators for a wider range of soil properties is needed.

In order to overcome the expense of traditional soil survey and the limitations of pedotransfer functions, researchers are increasingly turning to remote sensing and, in particular, reflectance spectroscopy. This form of earth observation can provide useful indicators for mapping and monitoring many environmental features such as geology and minerals (Bower and Rowan, 1996; Clark, 1999), vegetation and soil (Lewis, 2000; Ben-Dor et al., 2002; Sumfleth and Duttmann, 2007) and even ecological habitats (Tiner, 2004; Bock et al., 2005). With field and imaging spectrometers becoming increasingly sophisticated, there is potential for substantial improvement in the speed, reliability and resolution of soil analysis. Spectral analysis of soil cores with field or laboratory spectrometers could provide a new means of automated, rapid and objective profile evaluation, following the approach now being developed for mineral characterisation of geological cores (Mauger et al., 2004). In addition, new imaging spectrometers offer the prospect of detailed raster-based mapping of surface soil properties with higher spatial resolution than is possible with the current approaches.

\section{Spectral reflectance variation in soils}

Early studies of soil reflectance spectra over the visible (Vis, 400$700 \mathrm{~nm}$ ), near-infrared (NIR, 1300-1300 nm) and shortwave-infra$\operatorname{red}^{1}$ (SWIR, 700-1300 $\mathrm{nm}$ ) region described and classified different 'curve forms'. For example, Condit (1970) identified three types of curves amongst 285 soils from the United States, characterised by the overall shape of the spectral response and changes in slope over the wavelength range. However, no attempt was made to explain the spectral response in relation to physical or chemical properties of the soils. A more comprehensive study by Stoner and Baumgardner (1981) described five curve forms amongst 485 soils from the United States and Brazil, and also related specific absorption features to soil organic carbon and iron oxide content in the soil. However, most of the more recent research has investigated relationships between the soil properties and soil reflectance with the aim of predicting the physio-chemical properties of the soil.

The clay mineralogy in soils has been distinguished in several studies using the short wave infrared (SWIR) region of the spectrum (1300-2500 $\mathrm{nm}$ ) (Islam et al., 2003), and especially the $2200 \mathrm{~nm}$ absorption feature that is characteristic of clays (Ben-Dor, 2002). Soil texture and clay content have also been estimated from reflectance spectra, based on the depth of specific clay absorption features (Ben-Dor and Banin, 1995b) and statistical analysis of the whole curve form (Brown et al., 2006; Viscarra Rossel et al., 2006). In a limited study conducted in South Australia, relationships

${ }^{1}$ The SWIR is included in the NIR in some disciplines such as chemistry and reflectance spectroscopy. between soil texture and laboratory and hyperspectral image spectra from the Barossa Valley region were described (Ryan and Lewis, 2000, 2001).

Early studies observed that increasing soil organic carbon (SOC) lowered albedo across the whole visible, shortwave infrared and near-infrared (Vis-NIR-SWIR) reflectance spectrum (Stoner and Baumgardner, 1981; Henderson et al., 1992). However, there appears to be a threshold of $2 \%$ organic carbon below which the effect of SOC on soil reflectance is greatly reduced (Baumgardner et al., 1985). SOC has been predicted from various portions of the Vis-NIR-SWIR largely because it contains so many components. These components include compounds such as lignin (e.g. 2050 and $2351 \mathrm{~nm}$ ), cellulose (e.g. 1370, 1725, and $2347 \mathrm{~nm}$ ), pectin (e.g. 1320, 1582, 1761, and $2111 \mathrm{~nm}$ ) and humus (e.g. 1929 and $1932 \mathrm{~nm}$ ), which are optically active across this spectral region and are thought to overlap in places (Elvidge, 1990; Ben-Dor et al., 1997). SOC has been reliably predicted from both laboratory reflectance spectroscopy and image spectroscopy (Ben-Dor et al., 2002; Daniel et al., 2004). Some studies have focused on the VIS and NIR regions of the reflectance spectra (Krishnan et al., 1980; Vinogradov, 1981; Daniel et al., 2003; Brown et al., 2006) whereas others have used the SWIR region to predict SOC (Morra et al., 1991; Ben-Dor and Banin, 1995b; Viscarra Rossel et al., 2006). An Australian study was able to predict SOC from reflectance spectroscopy in the spectral range $1702-2052 \mathrm{~nm}$ in a simultaneous determination of moisture, organic carbon and total nitrogen (Dalal and Henry, 1986).

Iron oxide content of soils has been predicted from different spectral regions of the VIS-NIR-SWIR, based on characteristic absorption features at 550-650, 750-950 (Ben-Dor and Banin, 1995a) and 1406 and $2449 \mathrm{~nm}$ (Ben-Dor et al., 2006). The concentration of iron oxide as wind blown dust on mangrove foliage has been predicted using features at wavelengths: 518,746 , 927, 1261, and $1402 \mathrm{~nm}$ (Ong et al., 2003). Studies have also found that SOC as low as $1.7 \%$ can severely decrease the influence of iron oxide on the reflectance spectra in the VIS and NIR regions, and particularly decrease the definition of the $900 \mathrm{~nm}$ absorption band (Galvao and Vitorello, 1998).

The detection of soil carbonate in soils is complicated by its characteristic absorption feature shifting to longer and shorter wavelengths depending on the impurities present (Ben-Dor et al., 1999; Clark, 1999). Furthermore, the depths of these spectral features are dependent not only on the concentrations present but also on particle size and porosity (van der Meer, 1995). Despite this, correlations between absorption feature depth and carbonate concentration have been established (Ben-Dor and Banin, 1990). Correlations have also been established between carbonate concentration in soil and reflectance spectra based on changes in colour and albedo (Ben-Dor and Banin, 1995b; Ben-Dor et al., 1999).

The aim of this study was to determine the extent to which highresolution reflectance spectra in the visible, near-infrared and shortwave infrared regions $(400-2500 \mathrm{~nm})$ could be used as an indicator to predict selected surface soil properties. An increasing number of studies have examined the reflectance properties of soils from temperate, Mediterranean and tropical regions with moderate to high fertility properties but evidence from low fertility soils is still sparse. In this study we examine soils from a South Australian region that has a unique array of profile and landscape characteristics such as low nutritional content and strong texture contrast profile due to extensive weathering, low organic matter content and a high occurrence of salinity and sodicity. The economic and environmental importance of understanding variability in landscapes like these is becoming increasingly accepted and has been highlighted by recent research (Lyle and Ostendorf, 2011).

While some previous studies have applied mid-infrared spectroscopy (2500-25000 nm) to Australian soils (Janik and 


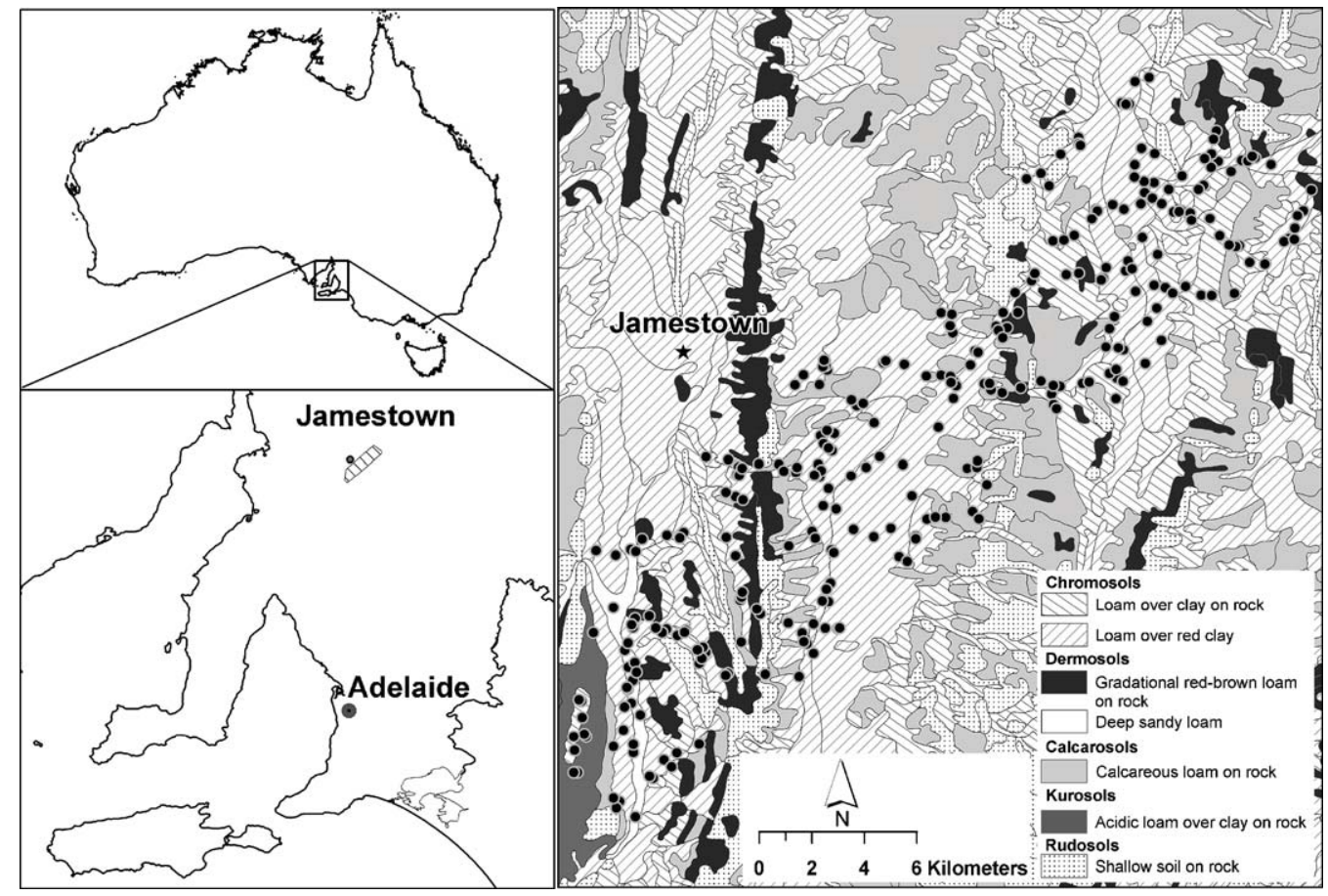

Fig. 1. Jamestown study site, $200 \mathrm{~km}$ north of Adelaide, South Australia. Polygons show Common Soils from the Land and Soil Spatial Data for southern South Australia [Soil and Land Program, 2007 \#570], soil sample sites marked with black dots. The legend describes the soil Order from the Australia Soil Classification (in bold) [Isbell, 2002 \#316] as well as the soil description from the Land and Soil Spatial Data for southern South Australia.

Skjemstad, 1995; Dunn et al., 2002), we examine the optical visible near-infrared range within which airborne and satellite-based imaging instruments operate $(400-2500 \mathrm{~nm})$. The study is a precursor to hyperspectral image mapping of soils in South Australian agricultural environments. For this reason, we focussed on properties that are important determinants of soil agricultural capability and the extent to which they can be simultaneously quantified and predicted from high-resolution reflectance spectra. In addition, we aimed to identify the spectral regions or features that are most influential in soil property discrimination, in order to guide future hyperspectral image enhancement and featureextraction methodologies. Many of the published spectral analyses of soils have focussed on single soil properties. Here we address the combined spectral expression of four key properties that are widely used to assess the agricultural and ecological capability of soils. Moreover, we examine the proposal that reflectance spectroscopy could be used as a cost effective means to improve the resolution of soil data for local and regional inventories. Therefore, we sampled soils to encompass the range of types and variability in properties that might be encountered in a regional mapping study. Most prior spectral studies have assembled collections of soils from geographically disparate areas to provide a wide range of characteristics for analysis. However, as an alternative (or complement) to traditional soil survey, the methodology needs to be able to predict properties within a limited region where variation is less pronounced. To further demonstrate the utility of Vis-NIR reflectance spectroscopy for supplementing soil maps, kriging was used to create continuous raster layers of the predicted soil properties.

\section{Methods}

\subsection{Study site and sample collection}

Soil samples were collected from the top $2 \mathrm{~cm}$ of 300 randomly selected sites in the Jamestown, Belalie district, approximately
$200 \mathrm{~km}$ north of Adelaide, South Australia (Fig. 1) (33.20611 ${ }^{\circ} \mathrm{S}$, $138.20611^{\circ} \mathrm{E}$ ). The northern third of the study site is dominated by a north-south trending range of hills. A broad valley extends into the south-eastern part of the study site and is interrupted by another, smaller north-south ridgeline. Several small ephemeral creeks also traverse the study site, some originating in the hills to the north-east and some outside the study area and running through the valley. Landuse in this area is predominantly rain fed cereal cropping in the low lying areas and perennial pasture in the hills.

Soils have been mapped at 1:100 000 by the Department of Water, Land and Biodiversity Conservation, South Australia (Soil and Land Program, 2007) and are predominantly Chromosols (Isbell, 2002), the key profile characteristic being a strong texture contrast between A and B horizons. These are described as Xeralfs within the Soil Taxonomy (Soil Survey Staff, 1999). Less widely distributed soils include Dermosols that have structure in A and B horizons and a gradational texture profile, Calcarosols that have carbonate in the profile and Rudosols which include shallow skeletal soils on rock. Textures of the B horizon are often heavy clays that are almost invariably underlain by a carbonate-rich clay horizon. In higher rainfall areas and some of the ranges there are isolated patches of Kurosols, which are acidic soils with a strong texture contrast between the A and B horizons.

\subsection{Laboratory soil analysis}

Proportions of clay were calculated from particle size analyses using the hydrometer method (Gee and Bauder, 1986; Sheldrick and Wang, 1993). It should be noted that this methodology calculates clay fraction as determined by size $(<2 \mu \mathrm{m})$ and not mineralogy. Therefore, other fine material $(<2 \mu \mathrm{m})$ such as iron oxides and silicates could be measured in this fraction if it is present in the soil. The calcimeter method (Allison and Moodie, 1982; Nelson and Sommers, 1986) was used to measure the carbonate concentration in the soil. Organic carbon was deter- 
mined by a modification of the Walkley and Black's titration method as outlined by Nelson and Sommers (1986). Iron oxide content was measured by the sodium dithionate-citrate method (Olson and Roscoe, 1986; Ross and Wang, 1993).

\subsection{Reflectance spectra}

Prior to spectral measurement, soil samples were air dried in an oven at $60{ }^{\circ} \mathrm{C}$ for $72 \mathrm{~h}$ and then passed through a $2 \mathrm{~mm}$ sieve. Samples were placed in a Petri dish and screeded so that the entire surface of the soil sample was level with the rim of the dish, thus guaranteeing a uniform sample depth of $10 \mathrm{~mm}$ and ensuring that reflectance measurements recorded the soil surface and not the sample background. Soil spectra were collected using a FieldSpec Pro spectrometer (Analytical Spectral Devices) that measures reflectance in 3-10 $\mathrm{nm}$ bandwidths over the range $350-2500 \mathrm{~nm}$. A high-intensity contact probe was used to optimise incidence and reflectance angles, minimise illumination differences and atmospheric attenuation of the signal and allow for precise identification of the area sampled. The quality of the spectral measurements was reviewed and noisy portions (350-400 nm) of the spectra were removed prior to analysis. The average of 10 spectra for each sample was used in subsequent statistical analysis.

\subsection{Statistical analysis}

The objective of the statistical analysis was to determine whether the reflectance spectra could be used to predict the chosen soil properties, and to identify the spectral regions contributing to the prediction. Multiple linear regression is a common multivariate tool which, at its simplest level, forms a model that specifies the relationship between a response variable $(Y)$ and a set of dependent variables $(X)$. However, multiple linear regression suffers from some significant limitations, the most important being the overfitting of data when there are large numbers of highly correlated variables (significantly more than the number of samples), as is often the case with hyperspectral reflectance measurements. Partial least squares regression was developed in order to overcome this limitation (Wold et al., 1983; Otto and Wegscheider, 1985), through the incorporation of aspects of principal components analysis and multiple linear regression. More specifically, partial least squares regression finds a series of components or latent vectors that provide a simultaneous reduction or decomposition of $X$ and $Y$ such that these components explain, as much as is possible, the covariance between $X$ and $Y$. This step approximates principal components analysis, although in the latter the components only explain variation in $X$ and do not necessarily have any bearing on $Y$. This is then followed by regression where $Y$ is predicted from the reduction of $X$ (Abdi, 2003). The number of latent vectors are chosen by a process of cross-validation which outputs a root mean square error (RMSE), with the aim of minimising both the number of latent vectors and the RMSE. Partial least squares regression has been used previously over different spectral ranges (Vis-NIR-SWIR-MIR) for the prediction of soil properties with varying degrees of success (Janik et al., 1998; Walvoort and McBratney, 2001; McCarty et al., 2002; Cozzolino and Morón, 2003; Ong et al., 2003).

Statistical analysis was carried out using The Unscrambler (Camo Software AS). Calibration data was mean centred and crossvalidation was used to determine the minimum number of PLS factors required. A large proportion of the samples recorded no carbonate in the laboratory analysis, with the result that the carbonate distribution amongst the 290 samples was strongly skewed. To provide a range of values more suitable for statistical analysis, the data set for carbonate analysis was reduced to 75 by randomly selecting samples that returned zero carbonate in the laboratory analysis to include in the statistical analysis along with all of the samples that contained higher carbonate levels. Crossvalidation was carried out using the 'leave-out-one' method where one sample is systematically left out from each cycle of the regression until all the samples have been excluded once. With different sample numbers for each of the soil properties examined, this method of validation was chosen to provide for a uniform approach for all of the analyses.

The accuracy of the prediction models was tested with the residual predictive deviation (RPD) which is the ratio of the standard error of performance to the standard deviation of the reference data (Williams, 2004). Interpretation of the RPD differs amongst authors and applications. However, it is generally accepted that when applied to the prediction of soil properties values below 1.5 indicate a poor predictive model, between 1.5 and 2.0 is acceptable and greater than 2.0 is considered good (Chang et al., 2001; Dunn et al., 2002; Cozzolino and Morón, 2003; Janik et al., 2007). Values below one are considered inadequate and indicate that the mean of the observed would be a better predictor (Williams, 2004).

\subsection{Spatial prediction}

The kriging function within the spatial prediction program VESPER (Minasny et al., 2005) was used to create raster surfaces of the measured and predicted surfaces. Local variograms were used for clay content, organic matter content and iron oxide content while low sample density required global variograms were used for carbonate content. Maps were created with $100 \mathrm{~m}$ cell size.

\section{Results and discussion}

\subsection{Soil properties}

The percentage of clay in the samples ranged from 5\% to $36 \%$ (Table 1), corresponding to textural classes loamy sand, sandy loam, loam, silty loam, silty clay loam, clay loam and clay (McDonald and Isbell, 1990). Values for organic carbon were between 0.3 and $2.9 \%$, carbonate concentrations $0-26 \%$ and iron oxide concentrations in the range $0.8-3 \%$.

\subsection{Soil spectral characteristics}

The overall form of the spectra for all the soils was quite similar. Clay (2200 nm) and water (1400 and $1900 \mathrm{~nm}$ ) absorption features were present in all spectra while there were differences in the albedo (intensity) and in the iron oxide $(850-900 \mathrm{~nm})$ and carbonate $(2300 \mathrm{~nm})$ spectral features amongst the samples.

Fig. 2 presents mean spectra for each of the quartiles from the laboratory analysis of clay. The quartiles were determined by dividing the samples into four groups based on their clay content, with each group containing $25 \%$ of the total range. Noteworthy is the increasing depth of the absorption features at approximately 1400,1900 and $2200 \mathrm{~nm}$ with increasing clay content. These absorption features are caused by bending and stretching in the

Table 1

Summary of laboratory results from chemical and physical analysis.

\begin{tabular}{lcccc}
\hline & $\begin{array}{l}\text { CC clay } \\
\text { content (\%) }\end{array}$ & $\begin{array}{l}\text { OC organic } \\
\text { carbon (\%) }\end{array}$ & $\begin{array}{l}\text { IO iron } \\
\text { oxide (\%) }\end{array}$ & $\begin{array}{l}\mathrm{CO}_{3} \text { carbonate } \\
\text { content (\%) }\end{array}$ \\
\hline No. of samples & 237 & 228 & 229 & 75 \\
Mean & 16.32 & 1.5 & 1.5 & 2.65 \\
Std. deviation & 5.42 & 0.53 & 0.37 & 5.37 \\
Minimum & 4.97 & 0.31 & 0.79 & 0.0 \\
Maximum & 35.98 & 2.9 & 3.05 & 25.67 \\
\hline
\end{tabular}




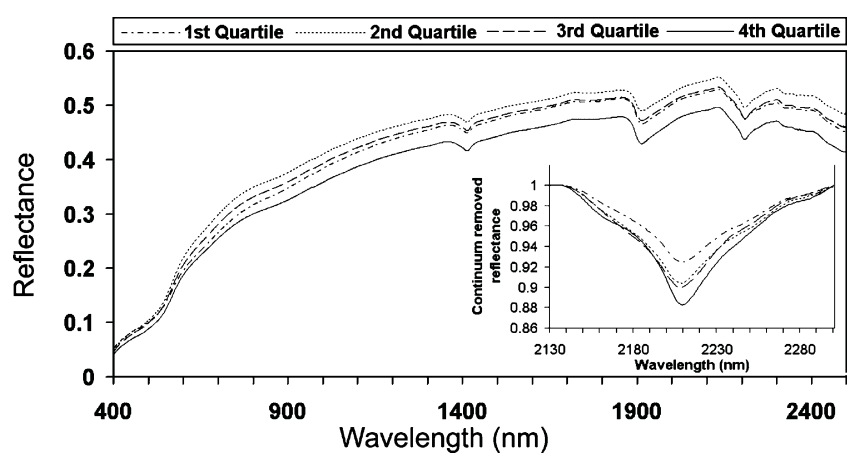

Fig. 2. Mean spectra of quartiles for percent clay.

$\mathrm{O}-\mathrm{H}$ bonds of free water ( 1400 and $1900 \mathrm{~nm}$ ) and the $\mathrm{Al}-\mathrm{OH}$ lattice structure in clay minerals $(2200 \mathrm{~nm}$ ) (Ben-Dor, 2002; Viscarra Rossel et al., 2006). Illitic and montmorillonitic clays dominate the study site area and the nature of the spectra supports this, as the single symmetrical absorption at $2200 \mathrm{~nm}$ is diagnostic for these clays. Other noticeable differences are evident in the VIS and NIR regions but are likely to be the result of other factors, such as SOC or iron oxides.

Fig. 3 shows the mean soil spectra of the quartiles from laboratory analysis for SOC. There is a clear trend with increasing SOC: the spectra have increased slope around $800 \mathrm{~nm}$ and lower reflectance across the $400-2500 \mathrm{~nm}$ spectral range, shifts which have been observed in other studies (Krishnan et al., 1980; Galvao and Vitorello, 1998). In addition to variation in SOC content, differences in albedo and the slope between 400 and $800 \mathrm{~nm}$ have been attributed also to the stage of organic carbon (OM) decomposition (Ben-Dor et al., 1997). The spectra here show increased absorption depth at 2327 and $2357 \mathrm{~nm}$, features which have been attributed to differences in the OM composition (BenDor et al., 1997). Although not investigated here, soils with a higher vegetative load will contain SOC over a range of decomposition stages.

Fig. 4 depicts the mean spectra for the quartiles of carbonate content. The carbonate absorption features were slight and limited to one spectral region $(2325 \mathrm{~nm})$. Although this appears to be the only spectral expression of carbonate in our samples, previous studies have used a range of wavelengths (1800, 2350, and $2360 \mathrm{~nm}$ ) to predict calcite in soils (Ben-Dor and Banin, 1990). Other spectral variations amongst our samples can only be attributed to other soil properties. The iron oxide quartiles in Fig. 5 demonstrate increasing definition of the iron oxide features in the VIS-NIR. As the iron oxide concentration increases, there is an increase in depth of absorption from 400 to $550 \mathrm{~nm}$ and in the broad feature at $900 \mathrm{~nm}$ indicating that goethite dominates the samples rather than hematite.

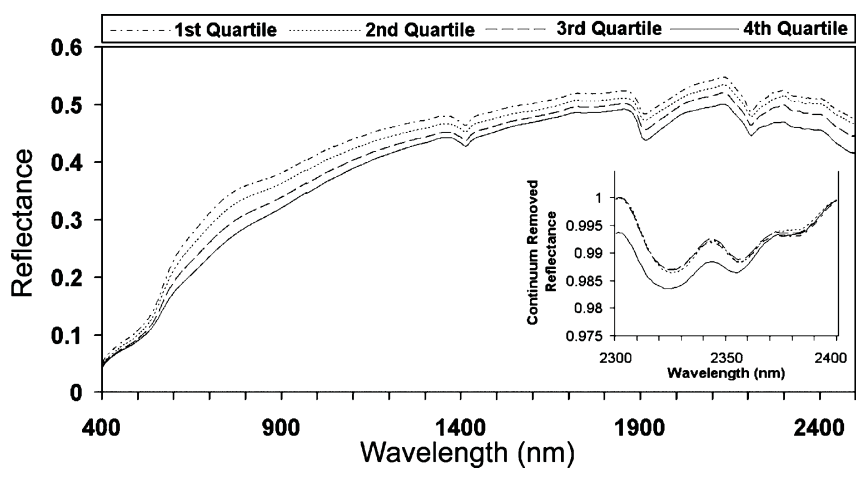

Fig. 3. Mean spectra of quartiles for soil organic carbon.

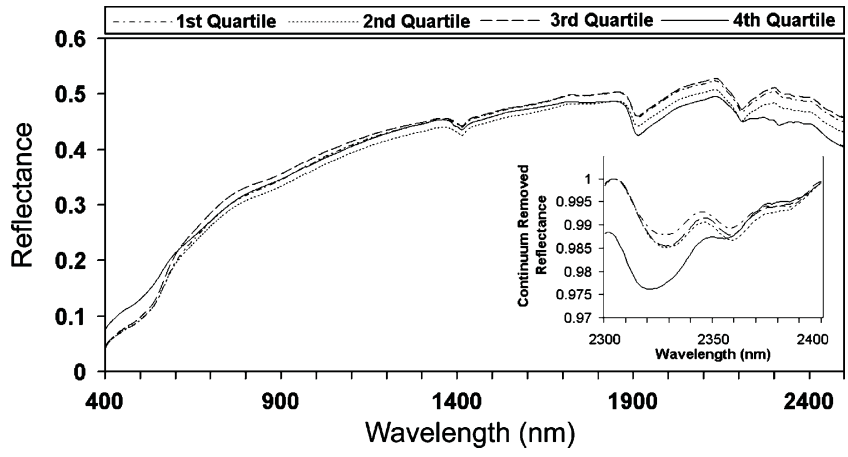

Fig. 4. Mean spectra of quartiles for carbonate concentration.

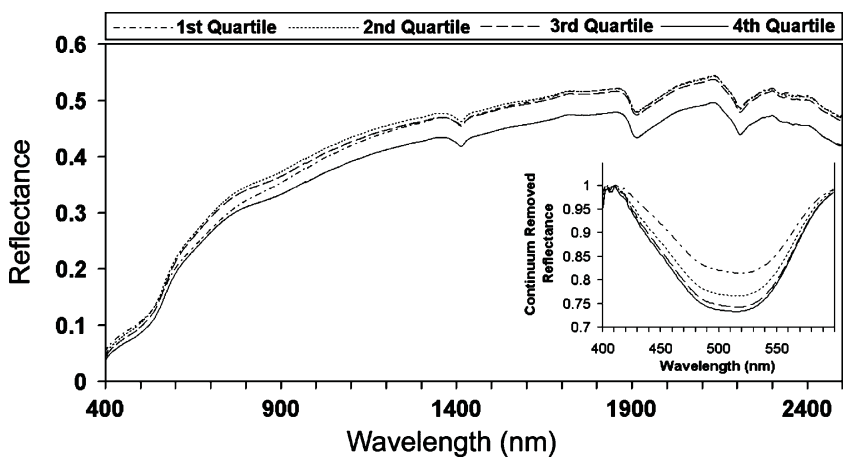

Fig. 5. Mean spectra of quartiles for iron oxide content.

\subsection{Prediction of soil properties}

Table 2 presents the efficiency criterion $(E)$, root mean square error (RMSE) and regression coefficients $\left(R^{2}\right)$ obtained from each partial least squares analysis. The first two PLS loading weights for each analysis in Figs. 6-9 demonstrate the relative importance of spectral regions in the prediction of each of the soil properties. Negative peaks in the loading weight graphs indicate spectral regions that correlate positively with the prediction and positive peaks are those areas that correlate negatively with the prediction.

With 10 prediction factors or latent vectors selected for the analysis (Table 2), 66\% of the variation in clay content was explained by the partial least squares regression model, returning a RMSE of 3.13. An RPD of 2.0 indicates that the prediction was acceptable and substantially better predictor than the mean of the observed clay contents. In Fig. 6 the first loading weight (PC1) is dominated by the clay absorption feature at $2200 \mathrm{~nm}$ and the features at 1400 and $1900 \mathrm{~nm}$. These three features are all related to the bending and stretching of $\mathrm{O}-\mathrm{H}$ bonds in the lattice minerals and water molecules, directly and indirectly associated with the clay minerals. The $2200 \mathrm{~nm}$ region is specifically related to the symmetric absorption feature that is diagnostic of the illite and

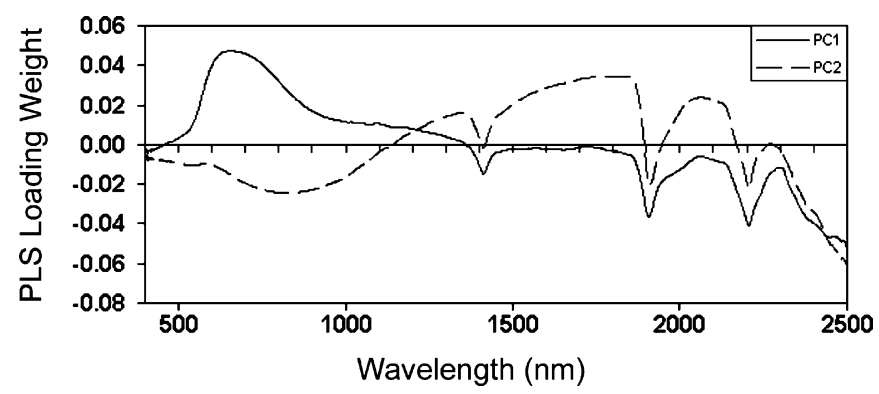

Fig. 6. Spectral loading weight graph for the prediction of clay content 


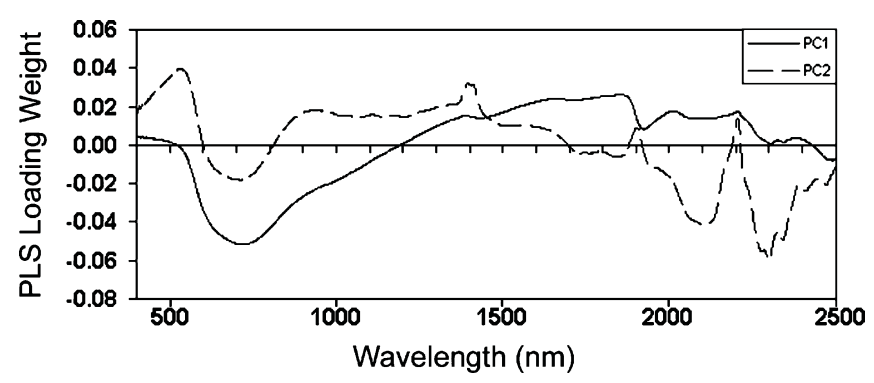

Fig. 7. Spectral loading weight graph for the prediction of soil organic carbon content.

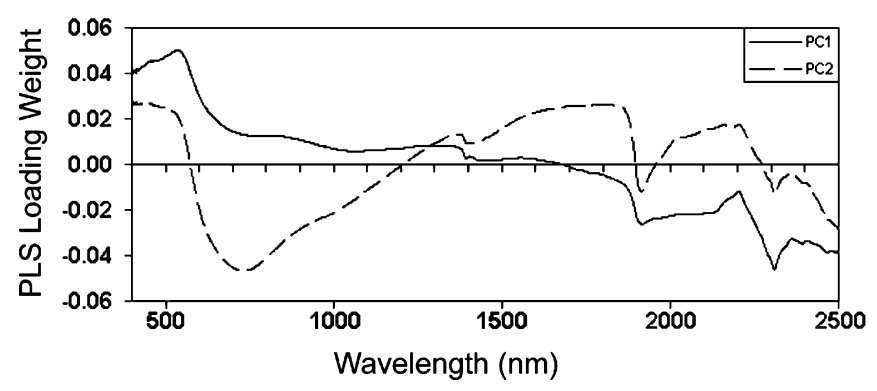

Fig. 8. Spectral loading weight graph for the prediction of carbonate content.

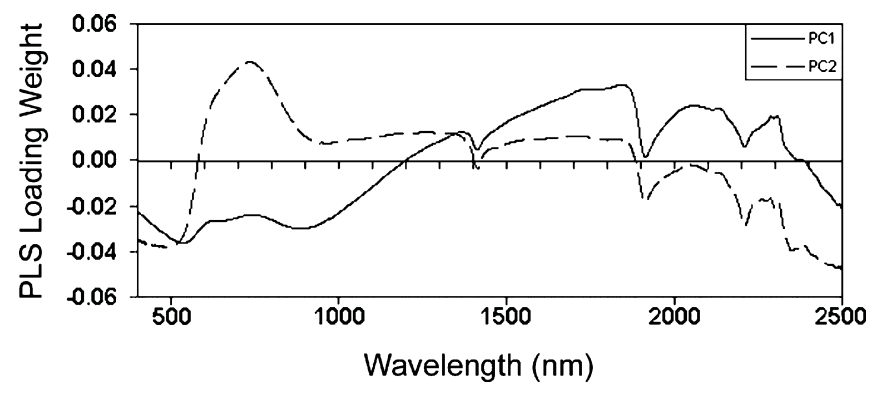

Fig. 9. Spectral loading weight graph for the prediction of iron oxide content.

montmorillonite that dominate the clays in these soils. For all these spectral regions, increasing clay content would result in more pronounced absorption features. These spectral regions were also discriminants for field textural classes in soils from the same geographic region (Summers et al., 2005). The second loading weight was dominated by the visible $(400-700 \mathrm{~nm})$ and a portion of near-infrared region (700-1300 nm) with some contribution from the same regions as observed in the first loading weight. The importance of the visible spectral range in this result indicates that there may be some co-variation between the clay content and the colour of the soil. There is also a strong influence in the first and second loading weights, starting at $2300 \mathrm{~nm}$ and increasing in contribution through to $2500 \mathrm{~nm}$. This is the initial stages of a water absorption feature that continues out of range to $2800 \mathrm{~nm}$.

The analysis explained $57 \%$ of the variation (Table 2 ) in SOC using 8 prediction factors with an RMSE of 0.35 . The RPD value of 1.8 is evidence of an acceptable model although it could be improved with different calibration strategies (Chang et al., 2001). The first loading weight was dominated by a relatively broad region extending from 550 in the visible to $1000 \mathrm{~nm}$ in the NIR, with a maximum contribution near $700 \mathrm{~nm}$ (Fig. 7). Increased SOC generally produces visibly darker soils and it is likely that this contributed to the prediction here. The second loading weight is dominated by a couple of peaks at 2100 and $2300 \mathrm{~nm}$. Other
Table 2

Sample numbers, residual predictive deviation (RPD), root mean square error (RMSE) and $R^{2}$ results for data sets.

\begin{tabular}{llclll}
\hline Soil property & Samples $(n)$ & Factors & RPD & RMSE (\%) & $R^{2}$ \\
\hline CC $(\%)$ & 237 & 10 & 2.0 & 3.13 & 0.66 \\
OC (\%) & 228 & 8 & 1.8 & 0.35 & 0.57 \\
IO (\%) & 229 & 10 & 1.7 & 0.23 & 0.61 \\
$\mathrm{CO}_{3}(\%)$ & 75 & 5 & 2.1 & 2.90 & 0.69 \\
\hline
\end{tabular}

studies have found these spectral regions to be associated with lignin and humic acids and important in the prediction of SOC (Ben-Dor et al., 1997).

Substantially fewer samples were available for the carbonate analysis than for the other soil properties (Table 1), but the coefficient of determination was the highest for all the soil properties in the study (0.69) using 5 prediction factors (Table 2). The analysis also returned an acceptable RPD value (2.1) and a reasonable RMSE (2.9) (Table 2). The first loading weight (Fig. 8) is dominated by a peak at $2300 \mathrm{~nm}$ which is directly associated with carbonate in reflectance spectra. There is also some influence from a peak at $1900 \mathrm{~nm}$ that extends into a 'plateau' to around $2100 \mathrm{~nm}$. The second loading weight shows a broad peak from 600 to $1100 \mathrm{~nm}$ indicating some influence from red visible wavelengths to the near-infrared range. A previous study of a similar set of soils also found that the visible region contributed to discrimination of carbonate classes but that the discrimination was dominated by absorption features associated with water $(1900 \mathrm{~nm})$, clay $(2200 \mathrm{~nm})$ and carbonate $(2300 \mathrm{~nm})$ (Summers et al., 2005).

The prediction of iron oxide explained $61 \%$ of the variability in the samples using 10 prediction factors with an RMSE of 0.23 (Table 2). The RPD value was 1.7, which is the lowest of all the soil properties examined in this study although still within the acceptable range. The first loading weight (Fig. 9) shows the range from 400 to $1100 \mathrm{~nm}$ to be most influential in the prediction. Within this range there are two maximum 'peaks' one at 550 and one at $900 \mathrm{~nm}$, both regions associated with spectral characteristics of iron oxide species. The second loading weight is dominated by a portion (400-550 $\mathrm{nm}$ ) of the visible range, associated with the blue and green, and peaks at 1900, 2200, and $2300 \mathrm{~nm}$, associated with water, clay and carbonate respectively.

\subsection{Mapping of predicted soil properties}

The kriged geographic distributions of the measured and predicted soil properties are displayed in Fig. 10. Comparison between the measured and predicted soil properties demonstrate similar patterns and value ranges for the soil properties examined. The two maps of clay content show lower values in the hills towards the north-east and in the sandy soils of the south-west although overall the area has limited variability. The most substantial difference between the two maps is in the centre where the predicted map demonstrates less variability. Organic carbon shows the greatest variation between the measured and predicted maps of all of the soil properties examined. However despite that, the overall pattern between the two maps is consistent. In both maps organic carbon content is lower in the valley areas which are dominated by cropping, while in the hills, which are predominantly pasture, there is a build up of organic carbon. The small band of sandy soils in the south-east has unexpectedly high organic carbon contents although this too could be the product of the pasture and forestry landuse in that area.

There are some minor differences between the measured and predicted carbonate maps, however the same trend is evident in both. The central portion of each map shows higher carbonate contents, particularly along the southern edge. Both the measured 

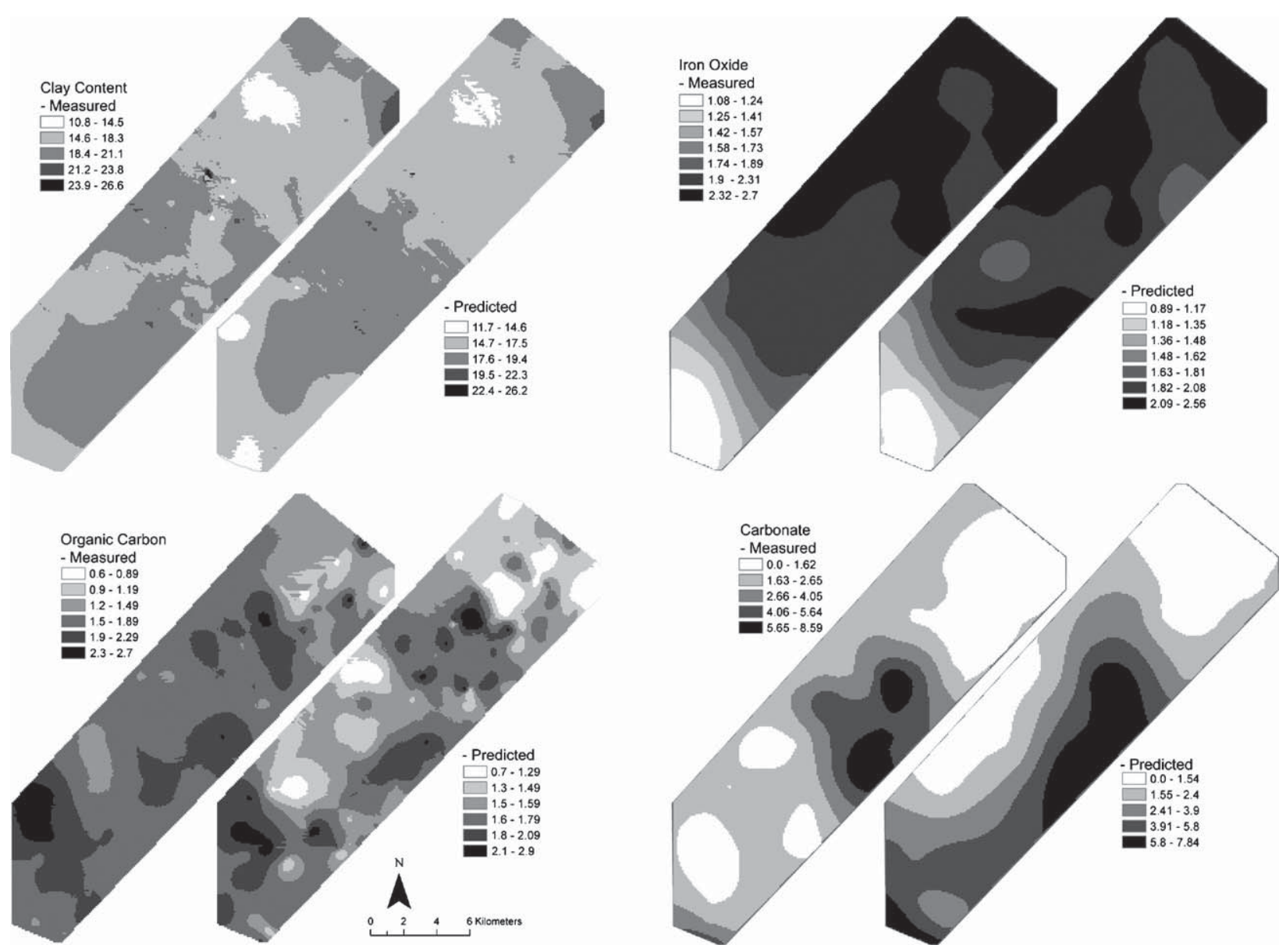

Fig. 10. Geographic distribution of predicted soil properties.

and predicted carbonate maps correspond well with polygons classed as calcareous within the Land and Soil Spatial Data (Fig. 1). The iron oxide maps show a good match between the measured and predicted soil properties, each demonstrating the same pattern and with a few small differences in the centre of the map. The area is dominated by red-brown earths and predicted iron oxide content reflects this with a relatively high and even distribution across the study site. The lower iron oxide levels in the south-west corner are associated with the small band of sandy soils found there.

\section{Conclusions}

Visible-near-infrared reflectance spectra collected under controlled laboratory conditions were employed as an indicator for the prediction of selected soil properties. Partial least squares regression overcame the collinearity problems associated with large numbers of highly correlated variables and relatively small sample numbers. We have shown that it is possible to predict clay content, soil organic carbon, iron oxide content and carbonate content from reflectance data produced with a high-resolution laboratory spectrometer. Furthermore, all of the samples were collected from the same geographical area in order to test prediction of soil properties over a naturally occurring range and provide a prediction that can be related to a regional image analysis. The predicted soil properties have also been examined geographically in relation to existing soil maps with some discussion of how they relate to the landscape and the usefulness of the method in future soil mapping projects. However, it should be noted that recalibration of PLS predictive functions would be required for different soil types and mineralogy.

Carbonate and clay content were best predicted followed by iron oxide and organic carbon. Validation $R^{2}$ for all analyses was above 0.5 and the RPD was acceptable for all soil properties. We showed the utility of particular regions of the $400-2500 \mathrm{~nm}$ spectrum for prediction of clay content (1900 and $2200 \mathrm{~nm}$ ), SOC (600-900 nm), iron oxides (400-1100 nm) and carbonate (1900$2300 \mathrm{~nm}$ ). This demonstrates the ability to use this methodology as an indicator for rapid and reliable soil mapping. Laboratory analysis of soil samples in support of traditional survey methods are expensive and time consuming. Field and laboratory measurement potentially offers a rapid, cost effective method for prediction of soil properties. Such studies could also be expanded to include the analysis of whole profiles and provide a more comprehensive understanding of the solum. Moreover, the results from this study can inform subsequent image studies which would allow the application of similar and related methodologies to spatially continuous remotely sensed imagery. However, further studies on different soils are required to confirm the efficiency of these predictors as indicators of soil properties and variability.

The Land and Soil Spatial Data in this region is produced at a relatively broad scale (1:100 000) and soil units are depicted with discrete polygons units. This provides a valuable regional planning tool but lacks the spatial resolution for finer scale applications. For example, the soil properties represented in any one polygon are, in some cases, only 50\% reliable (Soil and Land Program, 2007). This is largely the result of scale and the absence of soil variability depiction within polygons. The predictions of soil properties show that reflectance spectroscopy could be used to improve the spatial 
resolution of soil inventories such as these. Furthermore, we have demonstrated how simple kriging can be used to create a raster maps of the predicted soil properties and that these maps are comparable to the measured soil properties. It should be noted that there is room to improve the prediction accuracy of the reflectance spectroscopy in this study and achieving higher accuracy would benefit any soil survey carried out with these techniques. However, the improved spatial resolution available from greater sampling density at reduced costs could counteract some of the expected error.

While this study examines only surface soils, the spectral methodology would need to be extended to the profile to fully supplement traditional soil survey. Vis-NIR reflectance spectroscopy has been successfully used to catalogue and classify geological cores and in situ soil profiles (Mauger et al., 2004; Ben-Dor et al., 2008) and a combination of those techniques with the ones used here could provide a new methodology for complete description of the soil profile. These combined methodologies could be used to supplement traditional soil survey with the aim of improving the resolution of current soil mapping programs and to expand soil mapping to areas that are currently excluded due to economic imperatives such as arid and pastoral zones. It is also possible that the sampling density could be increased to the point where raster-based maps could be produced at reliably fine scales.

\section{References}

Abdi, H., 2003. Partial least squares (PLS) regression. In: Lewis-Beck, M., Bryman A., Futing, T. (Eds.), Encyclopaedia for Research Methods for the Social Sciences, Vol.. Sage Publications, Thousand Oaks, CA.

Allison, L.E., Moodie, C.D., 1982. Carbonate. In: Page, A.L. (Ed.), Methods of Soil Analysis, Vol. Soil Science Society of America, Madison, pp. 1379-1396. Analytical Spectral Devices, 2001. ASD Field Spec. Pro. Colorado.

Baumgardner, M.F., Silva, L.R., Biehl, L.L., Stoner, E.R., 1985. Reflectance properties of soils. Advances in Agronomy 38, 1-44.

Ben-Dor, E., 2002. Quantitative remote sensing of soil properties. Advances in Agronomy 75, 173-243.

Ben-Dor, E., Banin, A., 1990. Near-infrared reflectance analysis of carbonate concentration in soils. Society for Applied Spectroscopy 44, 1064-1069.

Ben-Dor, E., Banin, A., 1995a. Near-infrared analysis (NIRA) as a method to simultaneously evaluate spectral featureless constituents in soils. Soil Science 159, 259-270.

Ben-Dor, E., Banin, A., 1995b. Near-infrared analysis as a rapid method to simultaneously evaluate several soil properties. Soil Science Society of America Journal 59, 364-372.

Ben-Dor, E., Carmina, K., Heller, D., Chudnovsky, S., 2008. A novel combined optical method for (sic) objectively map soil in a near real time domain. In: The $21 \mathrm{~s}$ Congress of the International Society for Photogrammetry and Remote Sensing, Beijing, China, 3-11 July, p. 2008.

Ben-Dor, E., Inbar, Y., Chen, Y., 1997. The reflectance spectra of organic matter in the visible near-infrared and short wave infrared region $(400-2500 \mathrm{~nm})$ during a controlled decomposition process. Remote Sensing of Environment 61, 1-15.

Ben-Dor, E., Irons, J.R., Epema, G.F., 1999. Soil reflectance. In: Rencz, A.N. (Ed.) Remote Sensing of the Earth Sciences: Manual of Remote Sensing, vol. 3. John Wiley and Sons, New York, pp. 111-188.

Ben-Dor, E., Levin, N., Singer, A., Karnieli, A., Braun, O., Kidron, G.J., 2006. Quantitative mapping of the soil rubification process on sand dunes using an airborne hyperspectral sensor. Geoderma 131, 1-21.

Ben-Dor, E., Patkin, K., Banin, A., Karnieli, A., 2002. Mapping of several soil properties using DAIS-7915 hyperspectral scanner data-a case study over clayey soils in Israel. International Journal of Remote Sensing 23, 1043-1062.

Bock, M., Rossner, G., Wissen, M., Remm, K., Langanke, T., Lang, S., Klug, H., Blaschke, T., Vrscaj, B., 2005. Spatial indicators for nature conservation from European to local scale. Ecological Indicators 5, 322-338.

Bower, T.L., Rowan, L.C., 1996. Remote mineralogic and lithological mapping of the Ice River alkaline complex, British Columbia, Canada, using AVIRIS data. Photogrammetric Engineering and Remote Sensing 62, 1143-1376.

Brown, D.J., Shepherd, K.D., Walsh, M.G., Dewayne Mays, M., Reinsch, T.G., 2006. Global soil characterization with VNIR diffuse reflectance spectroscopy. Geoderma 132, 273-290

Camo Software AS, 2007. The Unscrambler 9.7. Oslo, Norway, http://www.camo. $\mathrm{com} / \mathrm{rt} /$ Products/Unscrambler/unscrambler.html.

Chang, C., Laird, D.A., Mausbach, M.J., Hurburgh Jr., C.R., 2001. Near-infrared reflectance spectroscopy-principal components regression analyses of soil properties. Soil Science Society of America Journal 65, 480-490.

Clark, R.N., 1999. Spectroscopy of rocks and minerals and principles of spectroscopy. In: Rencz, A.N. (Ed.), Remote Sensing for the Earth Sciences: Manual of Remote Sensing, vol. 3. John Wiley and Sons, New York, pp. 3-58.
Clarke, K.D., 2008. Landscape-scale Measurement and Monitoring of Biodiversity in the Australian Rangelands. PhD Thesis. University of Adelaide, Adelaide, South Australia.

Condit, H.R., 1970. The spectral reflectance of American soils. Photogrammetric Engineering 36, 955-966.

Cozzolino, D., Morón, A., 2003. The potential of near-infrared reflectance spectroscopy to analyse soil chemical and physical characteristics. Journal of Agricultural Science 140, 65-71.

Dalal, R.C., Henry, R.J., 1986. Simultaneous determination of moisture, organic carbon and total nitrogen by near infrared reflectance spectroscopy. Soil Science Society of America Journal 50, 120-123.

Daniel, K.W., Tripathi, N.K., Honda, K., 2003. Artificial neural network analysis of laboratory and in situ spectra for the estimation of macronutrients in soils of Lop Buri (Thailand). Australian Journal of Soil Research 41, 47-59.

Daniel, K.W., Tripathi, N.K., Honda, K., Apisit, E., 2004. Analysis of VNIR (400-1100 nm) spectral signatures for estimation of soil organic matter in tropical soils of Thailand. International Journal of Remote Sensing 25, 643652.

Dunn, B.W., Beecher, H.G., Batten, G.D., Ciavarella, S., 2002. The potential for nearreflectance spectroscopy for soil analysis-a case study from the riverine plain of south-eastern Australia. Australian Journal of Experimental Agriculture 42, 607-614.

Elvidge, C.D., 1990. Visible and near infrared reflectance characteristics of dry plant materials. International Journal of Remote Sensing 11, 1775-1795.

Galvao, L.S., Vitorello, I., 1998. Role of organic matter in obliterating the effects of iron on spectral reflectance and colour of Brazilian tropical soils. International Journal of Remote Sensing 19, 1969-1979.

Gee, G.W., Bauder, J.W., 1986. Particle-size analysis. In: Klute, A. (Ed.), Methods of Soil Analysis. Part 1. Physical and Mineralogical Methods, vol. 2. American Society of Agronomy - Soil Science Society of America, Madison, Wisconsin, USA, pp. 383-409.

Henderson, T.L., Baumgardner, M.F., Franzmeier, D.P., Stott, D.E., Coster, D.C., 1992. High dimensional reflectance analysis of soil organic matter. Soil Science Society of America Journal 56, 865-872.

Isbell, R.F., 2002. The Australian Soil Classification. CSIRO, Australia, Melbourne.

Islam, K., Singh, B., McBratney, A., 2003. Simultaneous estimation of several soil properties by ultra-violet, visible and near-infrared reflectance spectroscopy. Australian Journal of Soil Research 41, 1101-1114.

Janik, L.J., Merry, R.H., Forrester, S.T., Lanyon, D.M., Rawson, A., 2007. Rapid prediction of soil water retention using mid infrared spectroscopy. Soil Science Society of America Journal 71, 507-514.

Janik, L.J., Merry, R.H., Skjemstad, J.O., 1998. Can mid infrared diffuse reflectance analysis replace soil extractions? Australian Journal of Experimental Agriculture 38, 681-696.

Janik, L.J., Skjemstad, J.O., 1995. Characterisation and analysis of soils using midinfrared partial least squares. II. Correlations with laboratory data. Australian Journal of Soil Research 33, 637-650.

Krishnan, P., Alexander, J.D., Butler, B.J., Hummel, J.W., 1980. Reflectance technique for predicting soil organic matter. Soil Science Society of America Journal 44 $1282-1285$

Lewis, M., 2000. Discrimination of arid vegetation composition with high resolution CASI imagery. Rangeland Journal 22, 141-167.

Lyle, G., Ostendorf, B., 2011. A high-resolution spatial indicator of economic performance in the grain growing regions of Australia. Ecological Indicators $11,209-218$

Mauger, A.J., Keeling, J.L., Huntington, J.F., 2004. Bringing remote sensing down to earth: CSIRO Hylogger as applied to the Tarcoola goldfield, South Australia. In: 12 Australasian Remote Sensing and Photogrammetry Conference, Fremantle, Western Australia.

McBratney, A.B., Minasny, B., Cattle, S.R., Vervoort, R.W., 2002. From pedotransfer functions to soil inference systems. Geoderma 109, 41-73.

McCarty, G.W., Reeves III, J.B., Reeves, V.B., Follett, R.F., Kimble, J.M., 2002. Midinfrared and near-infrared diffuse reflectance spectroscopy for soil carbon measurement. Soil Science Society of America Journal 66, 640-646.

McDonald, R.C., Isbell, R.F., 1990. Soil profile. In: McDonald, R.C., Isbell, R.F., Speight, J.G., Walker, J., Hopkins, M.S. (Eds.), Australian Soil and Land Survey: Field Handbook, Vol.. Inkata Press, Melbourne.

Miller, T.F., Mladenoff, D.J., Clayton, M.K., 2002. Old-growth northern hardwood forests: spatial autocorrelation and patterns of understory vegetation. Ecological Monographs 72, 487-503.

Minasny, B., McBratney, A., Whelan, B.M., 2005. Vesper version 1.62. Australian Centre for Precision Agriculture, University of Sydney, Sydney, Australia, http:// www.usyd.edu.au/su/agric/acpa.

Morra, M.J., Hall, M.H., Freeborn, L.L., 1991. Carbon and nitrogen analysis of soil fractions using near-infrared reflectance spectroscopy. Soil Science Society of America Journal 55, 288-291.

Nelson, D.W., Sommers, L.E., 1986. Total carbon, organic carbon and organic matter. In: Page, A.L. (Ed.), Methods of Soil Analysis, vol. 2. Soil Science Society of America, Madison, pp. 53-579.

Olson, R.V., Roscoe, E., 1986. Iron. In: Page, A.L. (Ed.), Methods of Soil Analysis, vol 2. Soil Science Society of America, Madison, pp. 301-312.

Ong, C.C.H., Cudahy, T.J., Caccetta, M.S., Piggott, M.S., 2003. Deriving quantitative dust measurements related to iron ore handling from airborne hyperspectral data. Mining Technology 112, 158-163.

Otto, M., Wegscheider, W., 1985. Spectrophotometric multicomponent analysis applied to trace metal determinations. Analytical Chemistry 57, 63-69. 
Ross, G.L., Wang, C., 1993. Extractable Al, Fe, Mn, and Si. In: Carter, M.R. (Ed.), Soil Sampling and Methods of Analysis, Vol. Lewis Publishers, Boca Raton, pp. 239246.

Ryan, S., Lewis, M., 2000. Discrimination and mapping soils using HyMap hyperspectral imagery, Barossa valley, S.A.In: 10th Australasian Remote Sensing and Photogrammetry Conference, Adelaide.

Ryan, S., Lewis, M., 2001. Mapping soils using high resolution airborne imagery. In: Barossa valley, S.A. (Ed.), Inaugural Australian Geospatial Information and Agriculture Conference Incorporating Precision Agriculture in Australasia 5th Annual Symposium, Sydney, NSW, 17-19 July.

Sheldrick, B.H., Wang, C., 1993. Particle size distribution. In: Carter, M.R. (Ed.), Soil Sampling and Methods of Analysis, Vol.. Lewis Publishers, Boca Raton.

Soil and Land Program, 2007. Land and Soil Spatial Data for Southern South Australia - GIS format. (CD ROM). Department of Water, Land and Biodiversity Conservation, South Australia.

Soil Survey Staff, 1999. Soil Taxonomy: A Basic System of Classification for Making and Interpreting Soil Surveys. U.S. Government Print Office, Washington, DC.

Stoner, E.R., Baumgardner, M.F., 1981. Characteristic variation in reflectance of surface soils. Soil Science Society of American Journal 45, 1161-1165.

Sumfleth, K., Duttmann, R., 2007. Prediction of soil property distribution in paddy soil landscapes using terrain data and satellite information as indicators. Ecological Indicators 8, 485-501.

Summers, D., Lewis, M., Ostendorf, B., Chittleborough, D.J., 2005. Spectral discrimination of soil properties. In: SSC 2005 Spatial Intelligence, Innovation Praxis:
The National Biennial Conference of the Spatial Sciences Institute, Melbourne, Australia, September, p. 2005.

Tiner, R.W., 2004. Remotely-sensed indicators for monitoring the general condition of "natural habitat" in watersheds: an application for Delaware's Nanticoke river watershed. Ecological Indicators 4, 227-243.

van der Meer, F., 1995. Spectral reflectance of carbonate mineral mixtures and bidirectional reflectance theory: quantitative analysis for application in remote sensing. Remote Sensing Review 13, 67-94.

Vinogradov, B.V., 1981. Remote sensing of the humus content of soils. Soviet Soil Science 11, 114-123.

Viscarra Rossel, R.A., Walvoort, D.J.J., McBratney, A.B., Janik, L.J., Skjemstad, J.O., 2006. Visible, near infrared, mid infrared or combined diffuse reflectance spectroscopy for simultaneous assessment of various soil properties. Geoderma 131, 59-75.

Walvoort, D.J.J., McBratney, A., 2001. Diffuse reflectance spectrometry as a proximal sensing tool for precision agriculture. In: Third European Conference on Precision Agriculture, Montpellier.

Williams, P., 2004. Implementation of near-infrared technology. In: Williams, P., Norris, K. (Eds.), Near-infrared Technology in the Agricultural and Food Industries, Vol.. American Association of Cereal Chemists Inc., St. Paul, MN.

Wold, S., Albano, C., Dunn, W.J., Esbensen, K., Hellberg, S., Johansson, E., Sjöström, 1983. Pattern recognition: finding and using regularities in multivariate data. In: Martens, H., Russwurm, H. (Eds.), Food Research and Data Analysis, Vol. Applied Science Publishers, Essex, England, pp. 147-188. 